\title{
Entrevista com Jean-Paul Bronckart
}

\author{
Entrevistadora: \\ Anna Rachel Machado \\ (Pontifícia Universidade Católica de São Paulo - PUC-SP)
}

\begin{abstract}
RESUMO: Esta entrevista com Jean-Paul Bronckart foi conduzida durante a organização do XIV INPLA, realizado pelo Programa de Estudos Pós-graduados em Lingüística Aplicada e Estudos da Linguagem na PUC de São Paulo, no qual o Prof. Bronckart atuou como conferencista da sessão inangural e como debatedor de simpósio. Na entrevista, o autor nos mostra a trajetória de seus estudos e pesquisas, apresentando as razões que o levaram a se voltar para as questões do trabalho, assume suas fontes de referência centrais e a posiz̧ão de sua teoria em relação às outras disciplinas das Ciências Humanas, relata o desenvolvimento de suas relaçôes com os pesquisadores brasileiros, apresenta o desenvolvimento de seu pensamento, apontando para a necessidade de modificaç̃̃es em alguns aspectos da teoria apresentada em 1997 e discute sua posição em relação à dicotomia ciências básicas/ciências aplicadas.
\end{abstract}

PALAVRAS-CHAVE: Interacionismo Sócio-Discursivo, Vygotsky, Didática das Linguas, Análise de Textos/Discursos, Análise do Trabalbo.

ABSTRACT: This interview with Jean-Paul Bronckart was done during the organization of the XIV INPLA, which happened at the post-graduation programme of Applied Linguistics and Language Studies at PUC - SP. Professor Bronckart opened this event with a plenary conference and acted as debater in a symposium. In the interview, the author shows us his trajectory regarding studies and research, presenting the reasons why he got involved with issues about work, assumes his sources of central references and the position of his theory in relation to other disciplines of the Human Sciences, reports the development of his relationship with Brazilian researchers, presents the development of his thought, pointing out the need to change some aspects of his theory presented in 1997 and discusses his position concerning the dichotomy basic sciences/applied sciences. KEY-WORDs: Socio-Discursive Interactionism, Vygotsky, Didactic of Languages, Textual/Discursive Analysis, Analysis of the Work. 


\section{Introdução}

O interacionismo sócio-discursivo sofreu uma crescente divulgação no Brasil nos últimos dez anos, para o que muito contribuiu o Acordo Interinstitucional estabelecido entre a Universidade de Genebra (UNIGE) e a Pontifícia Universidade Católica de São Paulo (PUC/SP). Graças a esse acordo, um diálogo contínuo estabeleceu-se entre pesquisadores da Unidade de Didática de Línguas da Faculdade de Psicologia e Ciências da Educação da UNIGE e do Programa de Estudos Pós-graduados em Lingüística Aplicada e Estudos da Linguagem (LAEL) da PUC/SP. Dentre esses pesquisadores, os contatos mais contínuos tem sido feitos entre os professores Dr. Jean-Paul Bronckart - que coordenava o grupo de Genebra até mais ou menos 1998 -, Dr. Bernard Schneuwly, Prof. Dr. Joaquim Dolz, Prof ${ }^{a}$. Dra. Janette Friedrich, Prof ${ }^{a}$, Dr $^{a}$. Glaís Sales Cordeiro, Dr ${ }^{a}$. Itziar Plazaola-Giger, do lado suíço; e as professoras $\operatorname{Dr}^{\mathrm{a}}$. Roxane Rojo, Dr $^{\mathrm{a}}$. Maria Cecília Camargo Magalhães e Dr ${ }^{\mathrm{a}}$. Fernanda Liberali, além de mim mesma, Anna Rachel Machado, do lado brasileiro.

O diálogo estabelecido entre esses pesquisadores traduziu-se em inúmeras pesquisas, veiculadas continuamente em cursos, eventos científicos, assessorias (Rangel et al., 2001), processos de formação de professores (Magalhães, 1999), dissertações, teses, artigos, livros (Machado, 1998; Rojo, 2000; Dionisio, Machado e Bezerra, 2002; de Souza, 2003) e materiais didáticos (Machado, 2000 e 2004; Cristovão et al., 1998; Barbosa, 2001; Liberali et al., 2002) ${ }^{1}$. Mesmo com diferenças teórico-metodológicas visíveis entre si, os pesquisadores brasileiros citados guardam um traço em comum: a perspectiva de intervenção na educação, imediata ou prospectivamente. Em geral, suas pesquisas voltam-se para a atividade de ensino e aprendizagem da língua portuguesa, ou do francês e inglês como línguas estrangeiras, para a atividade de formação de professores e, mais recentemente, para a análise do ensino como trabalho. Todos esses trabalhos têm trazido conclusões e questionamentos que nos têm levado a desenvolver uma contínua reflexão sobre o interacionismo sócio-discursivo, ao mesmo tempo em que sua divulgação - seja da vertente "mais teórica" ou "mais

\footnotetext{
1 Por questão de espaço, as referências aos trabalhos de pesquisadores brasileiros que, de uma forma ou de outra, apresentam alguma relação com o ISD, são apenas uma amostra do conjunto dessas pesquisas.
} 
didática" 2 - tem multiplicado interpretações sobre seus conceitos de base e sobre o modelo de análise de textos proposto, que foi sintetizado na obra de Bronckart (1997), por nós traduzida para o português em 1999 (Bronckart, 1999).

Assim, durante o planejamento das atividades do XIV INPLA, propusemo-nos a organizar um simpósio sob o título "Painel de pesquisas brasileiras e portuguesas no quadro do interacionismo sócio-discursivo: aportes teóricos e metodológicos e novas tendências" (Machado \& Pinto, 2004), com o objetivo de propiciar um espaço de discussão de questões teóricas e metodológicas que têm emergido dos diferentes tipos de pesquisas que tomam o quadro teórico do interacionismo sócio-discursivo, na linha de pesquisa Linguagem e Educação, na de Linguagem e Trabalho e na de Linguagem e Novas Tecnologias e para também efetuar um levantamento das contribuições desse quadro teórico para a Lingüística Aplicada brasileira na última década. Tendo convidado o Prof. Dr. Jean-Paul Bronckart para exercer a função de debatedor desse simpósio, a Comissão Organizadora desse congresso logo se interessou também em convidá-lo para a conferência inaugural, sob o título "Restrições e liberdades textuais, inserção social e cidadania” (Bronckart, 2004). Decidimos então realizar uma entrevista com o Prof. Bronckart, com o intuito de apresentá-lo aos participantes do XIV INPLA que ainda não o conheciam e para elucidar suas filiações teóricas, conhecer melhor a trajetória de seu pensamento e do grupo que muito por tempo coordenou, assim como para tomar conhecimento de suas reflexões mais recentes. É o resultado completo ${ }^{3}$ dessa entrevista que apresentamos aos leitores da revista D.E.L.T.A..

A.R. - Quais são os fatos mais importantes que marcaram sua formação? Quais foram os autores/professores/movimentos que mais o influenciaram quando jovem?

J-PB - Minha formação inicial desenvolveu-se em duas etapas. De 1964 a 1969, na Universidade de Liège (Bélgica), me graduei em psicologia experimental e em psicologia da linguagem. De 1969 a 1974, na Universidade de Genebra, fiz estudos para a licenciatura em psicologia do desenvolvimento e depois desenvolvi uma tese de doutorado em psico-

2 As aspas aqui se justificam pelo fato de não acreditarmos nessa divisão estanque, principalmente no quadro do ISD.

3 Uma versão reduzida da entrevista foi colocada no site do XIV INPLA. 
lingüística do desenvolvimento. Durante esse período de formação, tive o apoio personalizado de dois professores que exerceram influência decisiva em meu percurso.

Em Liège, tive o privilégio de ter sido muito rapidamente integrado ao laboratório do professor Marc Richelle. Psicólogo generalista de inspiração skineriana, Richelle nos formou no rigor do método experimental e do raciocínio científico, ao mesmo tempo em que nos fazia ficar sempre interessados em conhecer outros paradigmas diferentes do behaviorismo: por exemplo, foi em seu laboratório que foram dados os primeiros cursos em francês sobre a teoria de Vygotsky e os primeiros cursos sobre a "Gramática gerativa" de Chomsky. Embora Richelle fosse adepto fiel do behaviorismo, ele deixava-nos completamente livres para fazermos nossas próprias opções. Do meu lado, aderi imediatamente e quase que espontaneamente à abordagem interacionista de Vygotsky, buscando combiná-la com alguns aspectos do behaviorismo metodológico. $\mathrm{Na}$ verdade, de forma global, continuei sempre fiel a essa orientação, como mostra, por exemplo, o artigo "Du behaviorisme à l'interactionnisme social", que publiquei em obra de homenagem a Marc Richelle (cf. 1995).

Mais tarde, logo que cheguei a Genebra, comecei a trabalhar no Departamento de Psicolingüística, que acabara de ser criado por Hermina Sinclair. Formada em lingüística histórica e comparada e aderindo depois à abordagem chomskiana e, sobretudo, ao construtivismo piagetiano, Sinclair, assim como Marc Richelle, tinha uma admirável abertura de espírito: todas as manhãs, das 7 h30 às 9 h30, ela dirigia um seminário informal em que eram discutidas leituras recentes, problemáticas teóricas, questões de metodologia etc. Esses seminários, dos quais participavam, dentre outros, Emilia Ferrero, Annette Karmiloff e Ioanna Berthoud, se constituíram como momentos de intensa formação para mim. Sinclair também orientou minha tese de doutorado, na qual tratei dos valores (temporais e/ou aspectuais) que as crianças de fato atribuem aos tempos verbais, no quadro de produções de enunciados em situação experimental. Já então, Sinclair aceitou que, no quadro desse trabalho, eu tomasse uma posição bastante crítica em relação à opção chomskiana e à piagetiana.

Em minhas escolhas pessoais, a primeira corrente teórica à qual aderi foi a que, naquela época, era conhecida como "psicologia soviética": meu trabalho de conclusão de curso foi inspirado nos trabalhos de Luria (para 
uma síntese, cf. Bronckart, 1971) e, através de Luria e de Leontiev (e dos cursos de Marc Richelle), fui progressivamente tomando consciência da importância da obra de Vygotsky. Vygotsky levou-me a Marx e a Spinoza e, desse modo, esses três autores (ou esse triunvirato) passaram a ser minhas referências centrais, continuando a sê-lo até hoje.

\section{Entrevista}

ARM: - Como se desenvolveu sua vida profissional na Universidade de Genebra? Quais foram as pesquisas mais importantes desenvolvidas? Com quais autores?

J-PB: - Posso considerar que minha vida profissional em Genebra desenvolveu-se em três etapas principais (atualmente, uma quarta etapa está se iniciando e será enfocada mais abaixo, em outra resposta). A primeira dessas etapas desenvolveu-se na Seção de Psicologia, de 1969 a 1976, apresentando três aspectos principais:

- Primeiro, o desenvolvimento de pesquisas em psicolingüística sob a orientação de Sinclair: minha pesquisa para a tese de doutorado sobre os tempos verbais (cf. Bronckart, 1976; Bronckart \& Sinclair, 1973) e pesquisas sobre as estratégias de compreensão da ordem das palavras (cf. Sinclair \& Bronckart, 1972) e sobre o papel que a linguagem exerce na regulação do comportamento motor (cf. Bronckart, 1973).

- A seguir, uma participação ativa, durante seis anos, nos trabalhos do Centro Internacional de Epistemologia Genética (CIEG), de Jean Piaget. Nesse quadro, especializei-me sobretudo na psicologia piagetiana, conduzindo diversas pesquisas experimentais (cf. Bronckart, 1974; Bronckart \& Cattin, 1974; Bronckart \& Rappe du Cher, 1977; Bronckart \& KarmilofSmith, 1978) e assistindo a debates profundos que eram realizados todas as semanas, nos quais intervinham, além do próprio Piaget, inúmeros cientistas, como L. Apostel, F. Bresson, P. Gréco, J. -B. Grize, F. Halwachts, B. Inhelder, J. Ladrière, S. Papert, A. Szeminska, R. Thom, além de muitos outros. Junto a outros contestadores, eu tinha, no CIEG, a reputação de ser mais vygotskiano que piagetiano, mas o próprio Piaget aceitava essa situação (que, logicamente, não podia incomodá-lo muito) e ele mesmo pediu-me para dirigir, a seu lado, um imenso volume da "Encyclopédie de la Pléiade" consagrado à psicologia (cf. Piaget, Mounoud \& Bronckart, 
1987). Esse trabalho só terminou bem depois da morte de Piaget, mas deu-me o privilégio de estar em contato muito estreito com esse extraordinário pensador durante os últimos anos de sua vida.

O último aspecto dessa primeira etapa de minha vida profissional na Universidade de Genebra configurou-se como uma busca pessoal de formação intensiva no campo da lingüística. Essa formação já havia começado em Liège, com um curso de iniciação à Gramática gerativa, prosseguindo em Genebra com o aprofundamento técnico nos métodos dessa teoria e também com um estudo aprofundado da semiologia, da teoria saussureana, da gramática estrutural, das teorias da enunciação de Benveniste e Culioli etc., o que acabou gerando a publicação de um manual de iniciação à lingüística (cf. Bronckart, 1977).

A segunda etapa de minha vida profissional desenvolveu-se de 1976 ao começo dos anos 80 e pode ser chamada de fase de transição... e de hesitações. Tendo manifestado interesse pela exploração pedagógica dos resultados das pesquisas em psicolingüística, a direção da Seção das Ciências da Educação convidou-me para conduzir, desde 1973, um curso de «psicopedagogia das línguas» e, em 1976, fui contratado como professor para esse campo de estudos. Esse período também foi marcado por um engajamento político e administrativo forte: desde 1978, com 32 anos, fui eleito presidente da Seção das Ciências da Educação, função que exerci por cinco anos, o que me permitiu implementar, ao lado de alguns colegas, uma reestruturação completa e um desenvolvimento significativo dessa seção. No plano científico, procurei, ainda com uma lógica «aplicacionista», explorar os resultados das pesquisas psicolingüísticas em prol da reforma dos programas e dos métodos de ensino do francês (cf. Bronckart, 1979; 1980). Essa tentativa foi um fracasso brutal e me fez compreender que as questões de formação em língua deveriam ser abordadas em outra perspectiva lingüística (não mais frasal, mas textual) e com outra concepção das relações entre as ciências da educação e as disciplinas de referência, representadas pela lingüística e pela psicologia, o que marcou a passagem de uma lógica psico-pedagógica a uma abordagem de « didática » das disciplinas escolares. Entretanto, antes de tentar desenvolver essa nova abordagem, dediquei-me a finalizar meu trabalho como psicolingüista, publicando diversas sínteses dos resultados a que tinha chegado em minhas pesquisas nessa área (cf. Bronckart, Gennari \& de Weck, 1981; Bronckart, Kail \& Noizet, 1983). 
A terceira etapa de minha vida profissional em Genebra, de 1980 até mais ou menos 1998, foi a do desenvolvimento da Unidade de Didática das Línguas, com a colaboração ativa de Daniel Bain, Bernard Schneuwly, Joaquim Dolz, Itziar Plazaola e de muitos outros professores-pesquisadores. Os trabalhos realizados por esse grupo podem ser divididos em quatro categorias principais:

- Primeiro, um amplo trabalho teórico e empírico, que teve por objetivo fornecer-nos um modelo coerente da estrutura e do funcionamento dos textos/discursos do francês contemporâneo. Com base na análise de milhares de trechos de textos, esse trabalho levou-nos à elaboração de uma grade de analise que permite detectar e quantificar as unidades e estruturas próprias aos tipos de textos, e a um primeiro modelo da estrutura dos textos, publicado em Bronckart et al. (1985). Esse tipo de pesquisa prosseguiu com um trabalho comparativo, com a aplicação do mesmo método de análise a outras línguas (alemão, basco, catalão, castelhano, italiano e português, por exemplo). Posteriormente, o modelo foi objeto de uma substancial formulação na obra "Activités langagières, textes et discours" (1997), traduzida por Anna Rachel Machado para o português (1999).

- A seguir, esses mesmos procedimentos serviram de referência de base para um conjunto de pesquisas sobre as "condições de aquisição dos principais domínios da organização” dos textos (tempos verbais, organizadores textuais, procedimentos de modelização etc.) por crianças ou alunos entre oito e treze anos. As pesquisas desse tipo foram essencialmente desenvolvidas em teses de doutorado por mim orientadas e que também apresentam uma dimensão comparativa (em particular, com o estudo do basco, do catalão, do espanhol e do italiano).

- A terceira categoria de trabalhos desenvolvidos nessa etapa foram trabalhos referentes à "didática das línguas". Nesse domínio, em colaboração com professores do nível primário (do $3^{\circ}$. ao $6^{\circ}$ ano) e do secundário inferior (do $7^{\circ}$ ao $9^{\circ}$ ano), contribuímos para a reforma dos programas de ensino de línguas da Suíça francofone (com uma nova abordagem da gramática e, sobretudo, com uma nova concepção do ensino de textos narrativos, argumentativos e informativos). Além disso, elaboramos dois tipos de instrumentos de ensino: manuais destinados ao ensino do francês para o $7^{\circ}, 8^{\circ}$ e $9^{\circ}$ ano, adotados e utilizados em diversos cantões da Suíça francofone (cf., por exemplo, Besson, Bronckart et al., 1990), e "seqüências di- 
dáticas", isto é, atividades-tipos estruturadas e centradas na maestria de um domínio específico do funcionamento da língua (cf. Dolz \& Schneuwly, 1998). Paralelamente, nesses anos, dirigi uma unidade de pesquisa e de intervenção no domínio da didática do esporte (cf. Bronckart, Brechbuhl \& Joanisse, 1985).

- A terceira categoria de trabalhos foram trabalhos mais teóricos, enfocando a epistemologia das ciências humanas (cf. Bronckart et al., 1996; Bronckart, 2002b), as conseqüências a serem tiradas da teoria saussureana do signo (cf. Bronckart, 2002a e 2003) e as teorias da ação (cf. Bronckart, 2001).

ARM - Suas pesquisas estiveram durante muito tempo ligadas às questões educacionais e, recentemente, voltaram-se para as questões de trabalho. O que motivou esse novo interesse?

J-PB - Essa mudança corresponde, de fato, a uma nova fase de meu trabalho (a quarta, considerando-se minha resposta anterior), mas pode-se considerar que é uma seqüência "natural" dos trabalhos anteriores. Quatro fatores principais podem explicar essa evolução:

- Nossos trabalhos sobre os textos tinham nos levado a considerar que eles são os "correspondentes empíricos" (em uma determinada língua) de uma atividade ou de uma ação linguageira. Assim, era natural que, conseqüentemente, começássemos a levantar questões sobre o estatuto, a definição e as condições de descrição do agir humano.

- Devido à minha ancoragem na filosofia de Spinoza e no marxismo, pareceu-me importante abordar essa questão do agir, considerando sua "historicidade", ou sob o ângulo daquilo que é sua manifestação mais determinante no tipo de sociedade em que vivemos, isto é, sob o ângulo do trabalho.

- Os trabalhos que desenvolvemos em didática das línguas inscreviam-se em um projeto de modernização e de "racionalização" dos projetos e dos métodos de ensino (cf. acima: reforma dos programas e criação de novos meios de ensino). Entretanto, como em outras didáticas das disciplinas (principalmente na didática das matemáticas), pareceu-nos necessário desenvolver pesquisas para avaliar os efeitos dos novos programas e dos novos métodos (em que medida eles trazem uma real melhoria do ensino e 
das aprendizagens?). Esse controle ou essa avaliação exigiam que fosse analisado o desenvolvimento efetivo das aulas. Para isso, foram realizadas pesquisas desse tipo, que, além de trazerem respostas às nossas questões iniciais, também mostraram a importância e a dificuldade do trabalho dos professores e suscitaram questões sobre a própria natureza desse trabalho.

- Enfim, devido a razões mais locais, parte da antiga Unidade de Didática das Línguas (parte à qual pertenço) decidiu integrar-se ao departamento de formação de adultos e, com essa integração, foi possível encontrar vários colegas que trabalham no domínio da ergonomia ou da análise do trabalho.

Tudo isso nos abriu espaço para a constituição de um subgrupo da Unidade de Didática das Línguas, denominado grupo "Langage, Action, Formation" (LAF), constituído por dez pesquisadores, que elaborou um amplo programa de pesquisa sobre "a análise das ações e dos discursos em situação de trabalho", sobre o qual não poderei discorrer suficientemente aqui (mais informações podem ser encontradas em nosso site da WEB, indicado abaixo).

ARM - Como se devolveram seus contatos com os pesquisadores brasileiros?

J-PB - Os primeiros contatos ocorreram em 1992, em Madri, durante o $1^{\circ}$. Congresso da Sociedade Internacional para a Pesquisa Sociocultural. Nessa ocasião, conheci Roxane Rojo e Maria Cecília C. Magalhães, do LAEL da PUC de São Paulo, e, pelas nossas exposições, constatamos que havia um forte parentesco entre nossas orientações: resumidamente, havia a focalização na linguagem e nos problemas de ensino de línguas e tínhamos como nossos autores de referência mais importantes, por um lado, Vygotsky e a escola soviética, no campo do desenvolvimento e Bakhtin, no campo da análise do discurso. Decidimos então estabelecer uma colaboração e a essa "decisão" se seguiram rápidos efeitos: intercâmbios entre professores e pesquisadores ocorreram desde o ano de 1993 e, em 1994, foi assinado um acordo de cooperação entre o LAEL e nossa unidade de didática, acordo esse que continua em vigor até hoje. Nesse quadro, co-orientei as teses de Anna Rachel Machado e de Glaís Sales Cordeiro (que trabalha atualmente em nossa unidade) e desenvolveram-se pesquisas coordenadas que resultaram na publicação, em 1999, de um número da revista "Pratiques et Théories", intitulada "Pratiques langagières et didactique des langues". 
Além disso, também temos contatos (menos formais e menos regulares) com pesquisadores em lingüística da Universidade Federal de Minas Gerais (Belo Horizonte), com pesquisadores de psicologia e ciências da educação da UNICAMP e da Universidade Federal do Rio de Janeiro e da Universidade de Vitória - Espírito Santo, na qual uma de nossas ex-doutorandas (Edivanda Mugrabi) atua atualmente como professora, desenvolvendo pesquisas sobre alfabetização.

ARM - Quais são as relações que sua equipe de trabalho tem com o Grupo ALTER do Programa do LAEL (PUC/SP) e com o projeto de pesquisa desse grupo?

J-PB - Principalmente pelo fato de que Anna Rachel Machado passou aproximadamente dois anos junto a nossa equipe em Genebra (e de que tem regularmente retornado) e também pelo fato de que ela também traduziu (brilhantemente) meu último livro para o português, tem sido sobretudo com essa pesquisadora do LAEL que temos desenvolvido uma colaboração de trabalho mais estreita. E, de um modo muito curioso e interessante, enquanto a evolução interna do LAEL e outras razões que Anna Rachel pode explicar bem melhor que eu levaram-na a constituir o Grupo ALTER, voltado para a análise das relações entre linguagem e trabalho educacional, a evolução interna da Unidade de Didática das Línguas de Genebra levou-nos, pelas razões acima mencionadas (cf. 3), a abordar a problemática da análise do trabalho em geral, dentre os quais, o trabalho dos professores. Considerando essa nova comunidade de interesses, estabelecemos uma segunda forma oficial de colaboração, a participação do Grupo ALTER no projeto de pesquisa do Grupo LAF, sobre o qual falamos acima (cf. 3). Operamos com os mesmos sistemas conceituais e com as mesmas metodologias, com a análise de seqüências de ensino, assim como com a análise de diferentes tipos de textos produzidos em relação a essas mesmas seqüências de trabalho (textos institucionais, entrevistas com os atores etc.). Um "corpus" considerável de dados já foi coletado e, embora o essencial desses dados ainda esteja por ser analisado e interpretado, esse trabalho já nos deu a oportunidade de produzir diversos artigos em coautoria, que deverão ser publicados ainda neste ano (cf. Bronckart \& Machado, no prelo; Machado \& Bronckart, no prelo), prevendo-se, evidentemente, que essa colaboração prossiga no decorrer dos próximos anos. 
ARM - Em seus trabalhos, você aborda questões de ordem filosófica, psicológica, lingüística e didática sobretudo. Em que disciplina seria adequado enquadrá-los ? Qual (is) é (são) a(s) questões central(is) que subjazem a esse trabalho ?

J-PB - Para responder resumidamente à primeira parte da questão, posso dizer que, por princípio, nosso trabalho não se inscreve em nenhuma dessas disciplinas em particular ou, se preferirmos, inscreve-se em cada uma delas! Essa posição decorre, em primeiro lugar, do fato de que contesto radicalmente os princípios do positivismo e principalmente a divisão/ recorte que esses princípios produziram nas ciências sociais/humanas (antropologia, economia, sociologia, etnologia, lingüística, psicologia, ciência da educação etc.). Essa posição decorre também de três princípios formulados pelos fundadores do interacionismo social no começo do século XX:

- de um princípio de Mead, segundo o qual o desenvolvimento do social (a elaboração dos fatos sociais e os mecanismos de socialização) e o desenvolvimento psicológico das pessoas são duas facetas de um único e mesmo processo;

- e de dois princípios de Vygotsky: o princípio de que não se pode trabalhar seriamente em ciências humanas sem clarificar sua posição epistemológica e seu questionamento, o que implica levar em consideração a parte do "corpus" filosófico que se centra nas questões do espírito, do social e da ação; e, em segundo lugar, o princípio de que a atividade prática é um objeto central de qualquer ciência do humano e que, conseqüentemente, essa ciência deve buscar teorizar as práticas, ao mesmo tempo em que intervém nessas práticas (em particular, no quadro da educação e da formação).

Além disso, considero que, como sustentava Saussure e como sustentam muitos pesquisadores até hoje, a atividade linguageira é um aspecto fundamental de toda prática social ou individual.

Conseqüentemente, posso dizer que me situo na ciência do humano, considerando que ela deve tratar, ao mesmo tempo, dos aspectos sociais, linguageiros, psicológicos e educacionais. Respondendo a segunda parte da questão, posso dizer que nosso trabalho está articulado a uma questão geral - quais são os processos que operaram no desenvolvimento (histórico) humano?-, questão essa que pode ser decomposta em várias subquestões: 
- Como caracterizar as propriedades universais das atividades linguageiras (enquanto textos e discursos produzidos no quadro de uma língua natural)?

- Que papel desempenha a maestria dessas atividades linguageiras nas formas de elaboração dos conhecimentos (tipos de raciocínio) e na formação de unidades de ação?

- Como os processos linguageiros mencionados podem gerar regras e normas que se cristalizam em instituições sociais e podem dar origem ao pensamento consciente humano?

- Em que e em quais condições, a atividade de trabalho e sua análise podem contribuir para o desenvolvimento e a formação das pessoas que trabalham?

ARM - Como você vê a relação de seu pensamento com o pensamento bakhtiniano ?

J-PB - Como quase todos os pesquisadores envolvidos com a análise de discurso, a descoberta do pensamento de Bakhtin foi muito importante para mim por quatro razões principais: pela ênfase que ele dá à diversidade das produções linguageiras, relacionando-as claramente à diversidade das atividades humanas; por sua perspectiva geral, que coloca a análise lingüística a serviço de problemáticas mais gerais (ao estatuto da literatura, da conversação etc.), por sua abordagem original e fundadora do estatuto dos gêneros de textos/discursos, pela introdução e desenvolvimento dos temas do dialogismo, do polilingüismo, da intertextualidade etc.

Isso posto, posso dizer ainda que, depois da recente clarificação do estatuto das obras do Círculo de Bakhtin e a atribuição definitiva a Voloshínov da paternidade exclusiva da obra "A estrutura do enunciado" e sobretudo de "Marxismo e filosofia da linguagem", meu interesse pela obra particular de Bakhtin diminuiu. Confesso preferir a abordagem de Voloshínov (como também a de Medvedev e, mais ainda, a de Jakubinski), cujo programa de trabalho e cuja orientação geral inspiraram profundamente a teoria que busco desenvolver (cf. Bronckart, 2002c).

ARM - Seu trabalho mais conhecido no Brasil é o livro « Atividades de linguagem, textos e discursos», publicado originalmente em 1997. De lá para cá, houve alguma modificação importante em seu pensamento? Ha alguma coisa nesse livro que você modificaria agora? 
J-PB - Na verdade, esse livro busca atingir dois objetivos que se interrelacionam, mas que são diferentes: por um lado, buscamos propor uma versão nova da arquitetura textual e das operações (psico-linguageiras) que subjazem aos diferentes componentes dessa arquitetura; por outro, no capítulo 1, buscamos propor o quadro, os conceitos e os questionamentos de nossa teoria sobre o desenvolvimento humano, a teoria do "interacionismo sócio-discursivo").

Em relação ao plano da estrutura geral de nosso modelo e da análise das distribuições de unidades e de estruturas lingüísticas, não há modificações importantes. Mas há duas necessidades de aprofundamento ou de complementação desse modelo. A primeira já veio apontada no próprio livro: o modelo não mostra com evidência suficiente as relações existentes entre a construção dos mundos discursivos (bases dos tipos de discurso) e as operações de responsibilização enunciativa. A segunda necessidade tem a ver com o caráter estático da definição e da análise das situações de produção textual: de fato, tal como se apresentam no livro, não consideramos de modo suficiente a dinâmica e a temporalidade dessa produção e as transformações de situação que podem se produzir durante o próprio decorrer da ação. Portanto, nesses dois casos, modificações/reconceitualizações significativas devem ser introduzidas, mas elas só poderão desenvolver-se com base nos resultados empíricos das pesquisas que atualmente se encontram em curso.

Além disso, nessa obra, adotamos essencialmente as concepções de ação oriundas da filosofia analítica, de Habermas e de Ricoeur. Nosso trabalho atual leva-nos a contestar a pertinência da primeira e a atenuar nossa adesão às duas outras. Para dar conta da dinâmica da ação, buscamos integrar a nosso modelo as abordagens da sociologia compreensiva de Simmel e de Schütz e a teoria do "poder de ação", que Giddens desenvolve atualmente.

No plano mais geral de nossa teoria do desenvolvimento, também se processaram modificações, particularmente sobre o conceito de ação (que definimos como uma unidade de funcionamento individual, em oposição à atividade como unidade de funcionamento coletivo).

ARM - O que pensa da Lingüistica Aplicada tal como se desenvolve no Brasil? Como você vê a validade das pesquisas teóricas e das pesquisas práticas ou intervencionistas? 
J-PB - Subjacente à questão dos termos adotados (e da oposição didática/lingüística aplicada), temos aí uma questão verdadeiramente importante, que é a da concepção das relações entre disciplinas e/ou pesquisas ditas básicas e as disciplinas, pesquisas ou campos ditos de aplicação. Para mim, essa diferença deve ser rejeitada por várias razões que já abordeít: por exemplo, a psicologia do desenvolvimento é considerada como uma disciplina básica, mas, a meu ver, seus trabalhos não têm nenhuma pertinência, se não integram dados de ordem educativa e didática (porque, em nossas sociedades, a educação é um dos espaços principais de desenvolvimento humano); e, em sentido inverso, as disciplinas ditas de campo (como a didática das línguas) não têm nenhuma pertinência, se não se baseiam em um domínio real das teorias de referência (no caso, das teorias lingüísticas). Um outro modo de dizer o que penso sobre isso é afirmar, para mim, todos os trabalhos das ciências humanas (da lingüística formal à análise do trabalho, passando pela psicologia cognitiva etc.) têm o mesmo estatuto, porque se confrontam com a mesma realidade: suas elaborações conceituais só podem ser validadas, "in ultimo", pela volta aos dados empíricos; e esses dados são sempre fatos de campo ou fatos práticos.

Uma vez esclarecida essa questão de fundo, a questão dos rótulos torna-se secundária. Pessoalmente, prefiro o rótulo «didática das línguas » em vez de "lingüística aplicada », já que, pelo que afirmei antes, não penso que se possa ou se deva « aplicar » a lingüística (e qual?) à educação. Mas o rótulo « didática » também traz problemas e pode ser fonte de confusão. Além disso, sabemos que a escolha desses rótulos pode depender também de problemas político-institucionais, sendo a lingüística aplicada reivindicada sobretudo pelas faculdades de letras e a didática, pelas faculdades da educação. Em suma, resumindo, o rótulo me importa pouco, me importa o que é realmente feito e a epistemologia que alimenta o trabalho de pesquisa. Como exemplo concreto, embora o LAEL seja uma unidade de lingüística aplicada, enquanto nosso grupo pertence a uma unidade de didática das línguas, o modo de pensar e de desenvolver as pesquisas nas duas unidades é globalmente o mesmo, sendo que, durante os dez anos em que temos trabalhado juntos, essas diferenças de rótulos nunca nos causaram o menor problema.

\footnotetext{
4 N.T. Ao que nos parece, Bronckart refere-se aqui a outros trabalhos por ele desenvolvidos sobre ess questão.
} 


\section{REFÉRÊNCIAS BibliográFICAS}

BARbosa, J. P. (coord). 2001. Coleção: Trabalhando com os gêneros do discurso: narrar. São Paulo: FTD.

Besson, M.J., Jean-Paul Bronckart et al. 1990. Français 8e. Pratique de la langue, Genebra, Cycle d'Orientation, 339 pp.

Bronckart, Jean-Paul. 1971. Le rôle régulateur du langage: critique expérimentale des travaux d'A.R. Luria, Neuropsychologia, 8, 451-463. \& H .Sinclair. 1973. Time, tense and aspect, Cognition, 2, 107130.

.1973. The regulating role of speech. A cognitivist approach, Human Development, 16, 417-439. Tradução: (1981). Papel regulador del lenguaje, Infancia y Aprendizaje, Monographie 1, 115-131.

.1974. La prise de conscience dans la sériation. In: J. Piaget, La prise de conscience, Paris, P.U.F., 235-260. Tradução: (1976). Seriation in the grasp of consciousness. In: J. Piaget, The grasp of consciousness, Cambridge, Mass, Harvard University Press, 300-331.

\& A. Cattin. 1974. La cohérence progressive dans l'interprétation des inversions en miroir et de la réfraction. In: J. Piaget, Recherches sur la contradiction, I, Paris, PUF, 125-147. Tradução: (1980). Progressive coherence in the interpretation of mirror images and refraction. In: J. Piaget, Experiments in contradiction, Chicago, Chicago University Press, 117-139.

1976. Genèse et organisation des formes verbales chez l'enfant, Bruxelas, Dessart \& Mardaga, 155 pp.

1977. Théories du langage. Une introduction critique, Bruxelas, Dessart \& Mardaga, 361 pp. Tradução: (1980). Teorías del lenguaje, Barcelona, Herder, 304 pp.

\& E. RAPPe DU CHER. 1977. Relations entre surfaces et périmètres des rectangles. In: J. PiageT, Recherches sur l'abstraction réfléchissante, II, 213-227.

\& A. KARMiLOFF-Smith.1978. Généralisations relatives à la pression et à la réaction. In: J. Piaget \& G. Henriques, Recherches sur la généralisation, Paris, P.U.F, 169-191.

\& al. .1979. Syntaxe de base et conjugaison à l'école primaire, Etudes de Linguistique appliquée, 34, 15-34.

.1980. L'acquisition de quelques notions grammaticales de base à l'école primaire, Enfance, 4/5, 321-322. 
, M. Gennari \& de G. Weck.1981. The comprehension of simple sentences. Ontogenesis of modes of processing in French, International Journal of Psycholinguistics, 8, 121-147.

, M. Kail \& G. Noizet (eds). 1983. Psycholinguistique de l'enfant; recherches sur l'acquisition du langage, Paris: Delachaux \& Niestlé, 294 pp. et al .1985. Le fonctionnement des discours. Un modèle psychologique et une méthode d'analyse, Paris: Delachaux \& Niestlé, 175 pp.

, J. Brechbuhl \& R. Joannisse. 1985. De la didactique des langues à la didactique du sport, Revue des Sciences et Techniques des A.P.S., 6, 61-68. 1995. Du behaviorisme à l'interactionisme social. In: H. LejeunE (Ed.), Des animaux et des hommes. Hommage à Marc Richelle, Paris, P.U.F., 255-292.

A. Clémence, Bernard Schneuwly, M. N. Schurmans. 1996. Manifesto. Reshaping humanities and social sciences: A Vygotskian perspective.Revue Suisse de Psychologie, 55 (2/3), 74-83. Traduction (1996): Manifesto: reformatando as humanidades e as ciências sociais, una perspectiva vygostkiana. in Revista Brasileira de Educação, 3, 64-74. 1997. Activité langagière, textes et discours. Pour un interactionisme socio-discursif, Paris, Delachaux et Niestlé. Tradução: (1999). Atividade de linguagem, textos e discursos. Por um interacionismo socio-discursivo, São Paulo, EDUC.

. 2001. S'entendre pour agir et agir pour s'entendre. In. J.-M. Baudouin \& J. Friedrich (Eds), Théories de l'action et éducation, Raisons Educatives, 4, 133-154.

. 2002 a. La culture, sémantique du social formatrice de la personne. In: F. Rastier et S. Bouquet, (Eds), Une introduction aux sciences de la culture, Paris, PUF, 175-201.

. 2002 b. La explicación en psicología ante el desafío del significado, Estudios de Psicologia, 23, 387-416

. 2002 c. Les processus de socialisation. Le déterminisme culturel et son dépassement, III Conference for Sociocultural Research: New conditions for knowledge production: globalization and social practices, CD-Rom, Universidade Estadual de Campinas, 28 pp.

. 2003. L'analyse du signe et la genèse de la pensée consciente, Cahiers de l'Herne, 76 - Saussure, 94-107.

. 2004. Restrições e liberdades textuais, inserção textual e cidadania. Conferência Inaugural. In: Caderno de Resumos do XIV INPLA Intercâmbio de Pesquisas em Lingüistica Aplicada. PUC-SP. São Paulo. 
\& Anna Rachel Machado. 2004. En quoi et comment les textes prescriptifs prescrivent-ils? Analyse comparative de documents éducatifs brésiliens et genevois. In: L. Filliettaz \& J.-P. Bronckart (Eds), $L$ 'analyse des actions et des discours en situation de travail. Concepts, méthodes et applications, Louvain, Peeters.

\& Anna Rachel Machado. No prelo a. Análise de documentos de prescrição educacional: Os «Parâmetros Curriculares Nacionais» e «Les objectifs d'apprentissage de l'école primaire genevoise», D.E.L.T.A., 2004.

Cristovão, Vera Lúcia Lopes et alii. (1998) Caderno de Inglês - Impulso Inicial. Estado do Paraná/Secretaria de Estado da Educação. Superintendência de Educação/ Departamento de Ensino de Primeiro Grau. 3 v.

De SouzA, Lusinete Vasconcelos. 2003. As proezas das crianças: das mal traçadas linhas ao texto de opinião. Campinas: Mercado de Letras.

Dionisio, Angela Paiva, Anna Rachel Machado \& M. A. Bezzerra (orgs) .2002. Gêneros de Texto e Ensino. Rio de Janeiro: Lucerna.

Dolz, J. \& B. Schneuwly. 1998. Pour un enseignement de l'oral. Initiation aux genres formels à l'école, Paris, ESF.

Liberali, Fernanda C., A. Shimoura, L. S. Abreu, E. Lousada \& M. C. Damianovic. 2002. Open House; Trabalhando com tipos de textos e temas transversais. São Paulo: Oxford University Press.

MACHADO, Anna Rachel. 1998. O diário de leituras: a introdução de um novo instrumento na escola. São Paulo: Martins Fontes. (Linguagem e texto).

. 2000. Uma experiência de assessoria docente e de elaboração de material didático para o ensino de produção de textos na universidade, DELTA, 16: 1: 1-25.

\& Rosalvo Pinto. No prelo a. Painel de pesquisas brasileiras e portuguesas no quadro do Interacionismo sócio-discursivo. IN: Caderno de Resumos do XIV INPLA - Intercâmbio de Pesquisas em Lingüística Aplicada. PUC-SP, São Paulo.

(org.) . No prelo b. O ensino como trabalho: uma abordagem discursiva. Rio de Janeiro: Lucerna.

\& Jean-Paul Bronckart. No prelo c. Procedimentos de análise de textos sobre o trabalho educacional. In. Anna Rachel MACHADO (org.), O ensino como trabalho: uma abordagem discursiva, Rio de Janeiro: Lucerna.

Magalhães, Maria Cecília Camargo.1999. La formation continue des enseignants: la scéance de réflexion comme espace de négociation entre 
enseignants. Pratiques langagières et didactique des langues. Cabiers de la section des Sciences de l'éducation, 9.: 215-247.

Rangel, Egon de Oliveira, Anna Rachel Machado, A. L. Garcia, M. C. C. MAGALHÃES. 2001. Um projeto para a universidade, suas utopias e sua problemática. ANAIS DA III CONFERÊNCIA DE PESQUISA SÓCIOCULTURAL, Campinas. 1370.doc

Rojo, Roxane H. R (org.). 2000. A prática de linguagem em sala de aula: Praticando os PCNs. São Paulo: EDUC; Campinas: Mercado de Letras. (As faces da Lingüística Aplicada).

Piaget, J., P. Mounoud \& Jean-Paul Bronckart (Eds.). 1987. La Psychologie, Paris, Gallimard, Encyclopédie de la Pléiade, 1960 pp.

SinCLAir, H. \& Jean-Paul BroncKart. 1972. S.V.O. A linguistic Universal? A Study in developmental psycholinguistics, Journal of Experimental Child Psychology, 14, 329-348.

Obs. Para a produção bibliográfica completa (e outros aspectos), ver o site http://www.unige.ch/fapse/laf

Tradutora: Anna Rachel MACHADO 